\title{
LIDAR OVERLAP FUNCTION DETERMINATION USING THE RAMAN LIDAR SIGNALS
}

\author{
Jaswant $^{1,2}$, Shishir Kumar Singh ${ }^{1,2}$, Radhakrishnan S.R. ${ }^{1,2}$, Devesh Shukla ${ }^{1}$, Chhemendra Sharma ${ }^{1,2}$ \\ ${ }^{I}$ Environmental Sciences and Biomedical Metrology Division, CSIR-National Physical Laboratory, Dr \\ K.S. Krishnan Marg, New Delhi 110012, India \\ ${ }^{2}$ Academy of Scientific and Innovative Research (AcSIR), CSIR Campus, CSIR Road, Taramani, Chennai \\ 600113, India \\ *Email: rkrishnan@nplindia.org
}

\begin{abstract}
The determination of vertical distribution of optical properties of clouds and aerosols using the lidar system is affected by the incomplete overlap between the field of view of transmitter i.e. laser beam $\&$ the receiver in the near-field range. Thus, the study of vertical profiles of aerosol optical properties in the lower atmosphere is erroneous without the correction of lidar overlap function. Here we have analysed the effect of overlap using a simple technique proposed by Ansmann and Wandinger to determine overlap function. We have determined the overlap factor for 5 different days of June 2016 and then calculated the mean overlap profile and determined the relative deviation of each day with respect to mean overlap factor. Results reveal that the complete overlap was achieved beyond 300 meters.
\end{abstract}

\section{INTRODUCTION}

In recent years, the lidar system has drawn greater attention for the measurement of optical aerosol properties at near altitudes due to increasing air pollution episodes. The lidar system can provide the range resolved measurements of optical properties of aerosols and clouds. However, the lidar observation is affected by the incomplete overlap between the transmitter and receiver field of view (FOV) in particularly at lower heights. This incomplete overlap makes a significant impact on the vertical profiles up to a few kilometres in the systems having a FOV as narrow as $0.5 \mathrm{mrad}$ or below. Without correcting the lidar backscattered signal for the overlap effects, it is not possible to study the boundary layer pollution and its sources using the lidar system.

There are several methods to analytically determine the overlap factor [2], by applying raytracing model [1], and also experimentally [3]. However, there are several limitations to these techniques since it requires us to know the technical parameters and we have to make an assumption of homogeneous aerosol environments. In this work we are using a simple technique proposed by Ansmann and Wandinger to determine the overlap function [4]. This method relies on the combination of elastic and Raman backscattered signals under clear atmospheric conditions.

\section{METHODOLOGY}

A Raman Lidar system has been deployed at the CSIR-Institute of Himalayan Bioresource Technology (IHBT), Palampur, Himachal Pradesh, India. The station is situated at an altitude of $1347 \mathrm{~m}$ (amsl). This lidar system is currently being used to obtain the vertical distribution of clouds and aerosol over Palampur.

\subsection{Experimental Setup}

Table 1 specifies the technical specifications of the Raman lidar system installed at Palampur. This lidar system has a space resolution of $7.5 \mathrm{~m}$ and operated at $355 \mathrm{~nm}$ (elastic channel) with Raman channel at $387 \mathrm{~nm}$. The return signal is detected in the binary format after which it is converted to ASCII format using the software provided by the manufacturer for further processing. The co-polarized and cross polarized Mie channels of the lidar system provides the linear depolarization ratio which is an indicator of the shape of the aerosol/cloud particle. The nitrogen Raman channel at $387 \mathrm{~nm}$ of the lidar system can be used to derive the lidar ratio, which is an important parameter for the identification of different types of aerosols in the troposphere.

Table 1 Lidar System Details

\begin{tabular}{|l|l|}
\hline \multicolumn{2}{|c|}{ Emitter } \\
\hline Laser Source & Nd:YAG (Quantel \\
\hline
\end{tabular}




\begin{tabular}{|c|c|}
\hline & ULTRA100 Series) \\
\hline Wavelength & $\begin{array}{c}355 \mathrm{~nm} \text { (frequency } \\
\text { tripled) }\end{array}$ \\
\hline Pulse Energy & $32.8 \mathrm{~mJ}$ \\
\hline Repetition Rate & $20 \mathrm{~Hz}$ \\
\hline $\begin{array}{l}\text { Near Field Beam } \\
\text { Diameter }\end{array}$ & $3.59 \mathrm{~mm}$ \\
\hline $\begin{array}{l}\text { Laser beam } \\
\text { divergence }\end{array}$ & $<0.8 \mathrm{mrad}$ \\
\hline \multicolumn{2}{|c|}{ Receiver } \\
\hline Telescope type & Cassegrain \\
\hline Primary Diameter & $200 \mathrm{~mm}$ \\
\hline Secondary Diameter & $48 \mathrm{~mm}$ \\
\hline Field of View & $\begin{array}{l}2.3 \mathrm{mrad} \text { (adjustable } \\
\text { from } 0.5 \text { to } 3 \mathrm{mrad} \text { ) }\end{array}$ \\
\hline \multicolumn{2}{|c|}{ Detection Unit } \\
\hline Transient Recorder & $\begin{array}{c}\text { Licel (20-12bit) with } \\
\text { 7.5m Raw Spatial } \\
\text { Resolution }\end{array}$ \\
\hline Detectors & 3 PMTs \\
\hline
\end{tabular}

\subsection{Sampling Site}

The sampling site is in Palampur located at the southern region of Western Himalayas and lies within the latitude $32.093^{\circ} \mathrm{N}$ and longitude $76.543^{\circ}$ E. Figure 1 shows the topographic map of Palampur. The experimental site is situated at Chandpur village which is at the altitude of 1347 $\mathrm{m}$ (amsl).

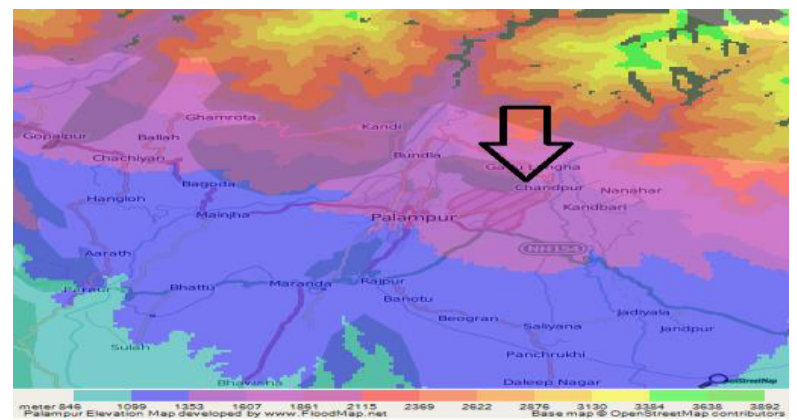

Figure 1: Topographic map of Palampur

\subsection{The Overlap Correction}

The lidar equations for both elastic and Raman channel are given as follows:

$$
\begin{aligned}
& \mathrm{P}_{\mathrm{o}}(z)=C_{o} O_{o}(z) z^{-2}\left[\beta_{\mathrm{o}, \mathrm{P}}(\mathrm{z})+\beta_{\mathrm{o}, \mathrm{M}}(\mathrm{z})\right] T_{o}^{2}(z)(1) \\
& \mathrm{P}_{\mathrm{R}}(z)=C_{R} O_{R}(z) z^{-2} \beta_{\mathrm{R}}(z) T_{o}(z) T_{R}(z)
\end{aligned}
$$

Here $P$ denotes received power and $0 \& R$ denote the wavelength of the laser at $\lambda_{0}$ and $\lambda_{R}$ is the Raman wavelength; system constants are denoted by $C_{0}$ and $C_{R}$ for both the elastic and Raman channels respectively; and $O(z)$ represents the overlap factor. The $O(z)$ reaches to zero near the lidar system (without overlap) and reaches to 1 in the time of complete overlap at large distances. The basic assumption made here in this approach is that $O_{0}(z)=O_{R}(z)[1]$.

From Eq. (1), $\beta_{0, P}$ and $\beta_{0, M}$ denote the backscatter coefficients for elastic channel at $\lambda_{0}$ for particles and molecules respectively. The nitrogen Raman backscatter coefficient at the wavelength $\lambda_{R}$ is denoted by $\beta_{R}$ in Eq.(2). Atmospheric transmission at $\lambda_{0}$ is represented by $T_{0}$ i.e. two way between the lidar and the backscatter region whereas $T_{R}$ at $\lambda_{R}$ is atmospheric transmission after the Raman scattering process along the way back to the lidar.

The iterative approach used here is based on the fact that the deviation between the Klett solution [5], [6] for the backscatter coefficient i.e. $\beta_{\text {Klett }}(z)$, determined from the elastically backscattered signal and the Raman solution [7] $\beta_{\text {Raman }}(z)$, contains the important information about the incomplete overlap [5].

This iterative approach makes use of the fact that the aerosol backscatter signal, after overlap and range corrections is directly proportional to the total backscatter coefficient (see Eq. (1)).

This iterative procedure to reduce the overlap effect on elastically backscattered signal is based on the aforementioned principle. As a first step $(i=1)$, we apply the Klett inversion method to the elastically backscattered uncorrected signal. The solution thus obtained is used to solve the expression:

$\Delta O_{i}(z)=\frac{\beta_{\text {Raman }}(\mathrm{z})-\beta_{\mathrm{Klett}, \mathrm{i}}(\mathrm{z})}{\beta_{\text {Raman }}(\mathrm{z})+\beta_{\mathrm{O} \cdot \mathrm{M}}(\mathrm{z})}$

The overlap correction to elastically backscattered signals is applied as follows: 
$P_{o, i+1}(z)=P_{o, i}(z)\left[1+\Delta O_{i}(z)\right]$

This signal profile $\mathrm{P}_{0,2}(\mathrm{z})$ is used as an input (step $i=2$ ) in the Klett method to derive backscatter coefficient $\beta_{\text {Klett,2 }}(z)$ and complete the next iteration. By repeating the same procedure again and putting $\beta_{\text {Klett }, 2}(z)$ into Eq. (3) we can derive a new $\Delta \mathrm{O}_{2}(z)$ which can be used in Eq. 4 again to correct the signal for overlap effect. This procedure is repeated till $10-12$ iterations so as to completely remove overlap effect. In each step, the new difference between $\beta_{\text {Klett }}(z)$ and $\beta_{\text {Raman }}(z)$ decrease. The final overlap profile is derived by comparing the improved signal with the measured signal.

\section{RESULTS}

We have used here the iterative method to successfully determine the overlap function at Palampur station. The results are shown in Figure 2(a) and 2(b) obtained on five days of June 2016 with the help of Raymetrics Raman lidar system. The Palampur has pristine environment and rainy conditions during this time of the year so a lidar ratio of $35 \mathrm{sr}$ at $355 \mathrm{~nm}$ is assumed for Klett inversion.
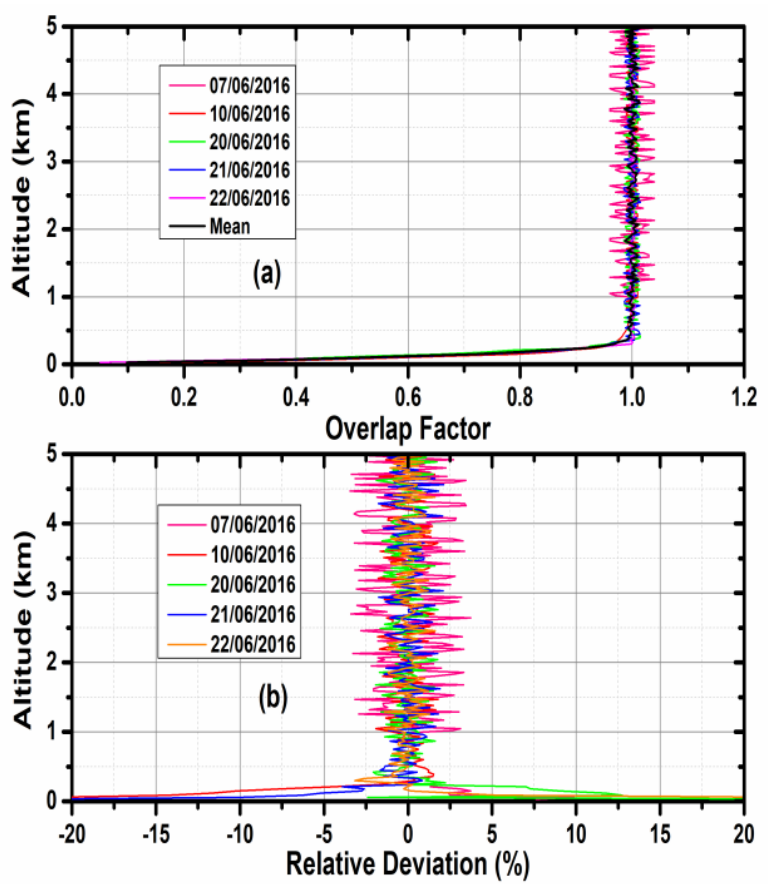

Figure 2(a) shows the overlap function calculated for the five days in the month of June 2016 with the mean overlap factor (black line) calculated using iterative method. Figure 2(b) shows the relative deviation of the overlap factor for 5 days with respect to mean overlap factor.
The results of Klett inversion and Raman inversion were derived and the solutions for several different iterations were derived using the method discussed in section 2.3. Here we have performed 12 iterations to determine the complete overlap height for each day. We have taken 5 different days of June 2016 and determined the overlap factor for each day and then computed the mean overlap profile with the relative deviation of each day with respect to mean. The results are shown in Figure 2(a) and 2(b). We can see from figure 2(a) that there was incomplete overlap below 300 meters and the complete overlap was achieved beyond 300 meters. Below 300 meters, the value of overlap function was less than 1 and after 300 meters, the value was close to 1 . Figure 2(b) shows the relative deviation of overlap factor calculated for each day with respect to mean overlap factor. The deviation above 300 meters was less than $5 \%$, however for lower heights i.e. below 300 meters the deviation was high.

\section{CONCLUSIONS}

It is important for the lidar users to have a proper knowledge about the geometrical form factor to remove or correct the lidar backscattered signals for the overlap effect which occurs at lower altitude due to the incomplete overlap between laser and telescope field of view. Here we have used an iterative approach to determine the overlap function. Results reveal that the lidar system was in complete overlap above $300 \mathrm{~m}$ and the lidar data has been applied with this correction. The overlap correction has helped us to determine the optical properties with improved results especially in planetary boundary layer.

\section{ACKNOWLEDGEMENTS}

Authors are grateful to Director, NPL for necessary support. Authors are thankful to CSIR network project PSC-0112 for necessary financial support. Mr. Jaswant is thankful to Council of Scientific and Industrial Research (CSIR) for providing research fellowship and also to Academy of Scientific and Innovative Research (AcSIR) for facilitating as its $\mathrm{PhD}$ student. 


\section{REFERENCES}

[1] R. Velotta, B. Bartoli, R. Capobianco, L. Fiorani, and N. Spinelli, Appl. Opt., 37, p. 6999 (1998)

[2] G. M. Ancellet, M. J. Kavaya, R. T. Menzies, and A. M. Brothers, Appl. Opt., 25, p. 2886 (1986).

[3] K. Tomine, C. Hirayama, K. Michimoto, and N. Takeuchi, Appl. Opt., 28, p. 2194 (1989)

[4] U. Wandinger and A. Ansmann, Appl. Opt., 41, p. 511 (2002)

[5] F. G. Fernald, Appl. Opt., 23, p. 652 (1984)

[6] J. D. Klett, Appl. Opt., 24, p. 1638 (1985)

[7] A. Ansmann, U. Wandinger, M. Riebesell, C. Weitkamp, and W. Michaelis, Appl. Opt., 31, p. 7113 (1992) 